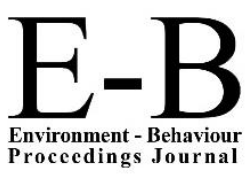

Environment - Behaviour
Procecdings Journal
AcE-Bs2016Taipei

$7^{\text {th }}$ Asian Conference on Environment-Behaviour Studies National Taiwan University, Taipei, Taiwan, 09-10 April 2016

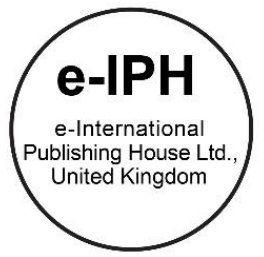

\title{
From Isovist to Spatial Perception: Wayfinding in Historic Quarter
}

\author{
Chih-Hung Chen ${ }^{1 *}$, Ting-Ju Lin, Chih-Yu Chen
}

${ }^{1}$ Department of Urban Planning, National Cheng Kung University, No.1, University Rd., East Dist., Tainan 70101, TAIWAN(ROC)

\begin{abstract}
Based on the assumption that human behaviours are mainly affected by physical and animate environments, this empirical research takes the changeful and complex historical district in Tainan to observe wayfinding behaviours. An a priori analysis of the isovist fields is conducted to identify spatial characteristics. Three measures, the relative area, convexity, and circularity, are applied to scrutinize the possible stopping points, change of speed, and route choices. Accordingly, an experiment is carried out to observe spatial behaviours and different influences of social stimuli. Results show that social interactions afford groups and pairs to perform better than individual observers in wayfinding.

(c) 2016. The Authors. Published for AMER ABRA by e-International Publishing House, Ltd., UK. This is an open access article under the CC BY-NC-ND license (http://creativecommons.org/licenses/by-nc-nd/4.0/).

Peer-review under responsibility of AMER (Association of Malaysian Environment-Behaviour Researchers), ABRA (Association of Behavioural Researchers on Asians) and CE-Bs (Centre for Environment-Behaviour Studies), Faculty of Architecture, Planning \& Surveying, Universiti Teknologi MARA, Malaysia.
\end{abstract}

Keywords: wayfinding; isovist; spatial perception and social stimuli; historic quarter

\section{Introduction}

Physical environment set-up is one of the main factors affecting human behaviours. Yet the descriptions of the environment and the mechanism of stimulation have been under debate among psychologists for decades (Gibson, 1960; Michaels, 2000). The theory of information pickup, as proposed by Gibson (1979), argues that the environment should be considered as a source of stimulation. The observer perceives the external stimuli, extract information, and respond to the properties as well as the changes in it (Gibson, 1966; Gibson, 1992; Adolph \& Kretch, 2015; Shamsuddina, Bahauddinb, \& Azizc, 2012). The ecological approach to perception opens the door for measuring possible perceptions and predicting locomotion in the physical environment. The causality between perceptiocognitive systems and actions has been studied further in several wayfinding experiments (Evans, Fellows,

${ }^{*}$ Corresponding author. Tel.: +886 6 2757575-54229; fax: +886 62754943.

E-mail address: chihhungchen@mail.ncku.edu.tw

2398-4287 @ 2016. The Authors. Published for AMER ABRA by e-International Publishing House, Ltd., UK. This is an open access article under the CC BY-NC-ND license (http://creativecommons.org/licenses/by-nc-nd/4.0/).

Peer-review under responsibility of AMER (Association of Malaysian Environment-Behaviour Researchers), ABRA (Association of Behavioural Researchers on Asians) and CE-Bs (Centre for Environment-Behaviour Studies), Faculty of Architecture, Planning \& Surveying, Universiti Teknologi MARA, Malaysia.

DOI: http://dx.doi.org/10.21834/e-bpj.v1i3.374 
Zorn, \& Doty, 1980; Hashim \& Said, 2013; Mohammad, Saruwoono, Said, \& Hariri, 2013; Monfared \& Yazdanfar, 2015) to identify exploratory strategies and the cognitive strategies (Ittelson, 1973). However, there's only a small number of experiments are conducted in real settings and even less in historical quarters.

Modern city planning on old fabrics has created a hybrid physical environment set-up of two different properties (Hussain \& Ujang, 2014; Ghoomi, Yazdanfar, Hosseini, \& Maleki, 2015; Shamsuddina, Sulaimana, \& Amatb, 2012). As a common feature of the old towns in Taiwan, the effects of the juxtaposition on pedestrian orientation remain unknown to readers (Ja'afara, Sulaimanb, \& Shamsuddinb, 2012). In common situations when pairs or groups of people are involved, they afford each other social interactions through the communication of knowledge or secondhand perception (Gibson, 1966). The affordance of the animate environment plays an important part in wayfinding, but still few literatures have focused on the subject.

With a purpose to shed light on the above issues, this empirical research takes the historical district in Tainan to investigate human reactions to the changing environments in pedestrians' perspectives (Chandraa \& Bhartib, 2013). The study consists two parts: a computational analysis of the area to identify the spatial characteristics, and a corresponding experiment to verify the a priori analysis in real settings (Abbasia, Alalouchb, \& Bramley, 2016).

\section{Review of literature}

\section{Description of the visual environment}

According to Gibson's theory, the environment is composed of variant and invariant substances. Men can easily distinguish the difference between the two as the invariants are permanent and constitute the layout of the environments. Being described as a field of light born information (Benedikt, 1979), the "layout of surfaces" (Gibson, 1979) gives structures to the ecological optics. During movements, the observer is able to extract information from the ambient optic arrays and the changing intensity of stimulation.

The possible visual perceptions at the observer's position, or isovist, can thus be computerized in the 2D abstraction developed by Benedikt and Davis (1979). By laying a regular grid (Batty, 2001; Turner, Doxa, O'Sullivan \& Penn, 2001), the areas, perimeters, visible perimeters, occlusivity, and compactness of the isovist fields can be measured to elucidate the spatial properties at each possible observation point. The shapes and sizes of isovist fields are of particular importance since they are unique to the observer's position; a change in the isovist field implies a transition in space. Accordingly, the characteristics of the place can be identified in the analysis. Research has also proved the correlation between isovist fields and spatial behaviours in indoor spaces (Meilinger, Franz, \& Bülthoff, 2012; Franz \& Wiener, 2008).

Wayfinding Experiment

In recent studies, wayfinding is regarded as a series of execution processes (Passini, 1984; Koseoglu \& Onder, 2011). Accumulative information from the environment is available with each step forward, leading to a decision and an associated behaviour in response to the place characteristic. The perceiving-acting function forms a close feedback loop in the process. During navigation, the observer constantly interacts with the environment, reforming and renewing his knowledge, and trying to find the best strategy (Kato \& Takeuchi, 2003; Cenani, Arentze, \& Timmermans, 2012). The universality of people's plans in settings is found in places with adequate information provided (Passini, 1980/1981; Passini, 1996; Bednarz \& Lee, 2011), in other words, people tend to apprehend and react to images in similar ways.

However, the environment usually contains too many messages than one can absorb that people only obtain the relevant information to their tasks. This leads to individual differences in wayfinding performance (Ittelson, 1973; Imani \& Tabaeian, 2012). Studies showed that the awareness of orientation, memory for landmarks, ages, genders, different strategies and knowledge may all contribute to various wayfinding behaviours (Takeuchi, 1992; Kozlowski \& Bryant, 1977).

Social Interaction

Physical environments and animate environments are in fact inseparable because people interact and communicate with each other (Durairaj \& Umar, 2015). When more than two people are present, a behavioral loop is 
established when the movement of the first partner stimulates the second, and the resulting movement reciprocally stimulates the first (Gibson, 1966; Runcharoen, 2014). Social interactions, serving as mutual or reciprocal stimuli, may be significant influences on orientation. The observers can impart past perceptions to others by verbal words or pictures to pass down the knowledge (Gibson, 1979; Parvaneh, Arentze, \& Timmermans, 2011; Wakabayashi, Itoh, \& Nagami, 2011).

\section{Research design}

\section{Method}

In this paper, the historic townscape in Tainan is converted into "isovist fields" in the computational analysis to examine the spatial qualities and predict possible perceptions. The abstraction provides a general description of the environment. The empirical experiment was conducted accordingly, under the assumption that observers could obtain additional information about the environment through social interactions and perform better in wayfinding. Subjects were then asked to walk in the historical quarter, as divided into groups, pairs, and individuals, to simulate different levels of social stimulation. The results were compared with the isovist analysis and between different numbers of participants to elucidate wayfinding behaviours.

\section{Setting}

Tainan, as one of the oldest cities in Taiwan, has become the synthesis of winding traditional alleys and western grid systems. The historical quarter, composed of mainly traditional alleys and one planned street running across in the middle, is chosen to investigate wayfinding behaviours. Compared with the modern planned roads framing the district, the widths of the traditional alleys are relatively narrower and usually between two to four meters. The streets have neither shade nor protrusion from the buildings alongside. Closer to human scale, the alleys allow pedestrians to get a closer look at the building facades.

The district is not easily subject to change because of the complicated plot divisions and has preserved the townscape for decades. Being spontaneously built along the existing paths or around the temples, the street spaces are irregular with a different orientation. The changeful and complex spaces provide sudden or gradual views of new intersections, squares, or vistas.

\section{A priori analysis: isovist field}

\section{Isovist measures}

A grid of $1.25 \mathrm{~m}$ is adopted, which is considered as the minimum space for a pedestrian (Neufert, 2009, p. 41). Based on Benedikt's theory (1979), three measures are used in this paper to translate the spatial properties of the district.

(a) "Relative area" evaluates the spacious or narrow qualities of a place. In a narrow area, fewer sheaves of light are available at the observer's position and produces a sense of insecurity, and vise versa (Stamps, 2005). Because people view spaces in relative levels, a comparative standard is applied here to approximate the visual illusions caused by the juxtaposition of contrasting spaces (Cullen, 1966). The formula is as below.

$$
A_{r i}=\frac{A_{i} \quad A_{\min }}{A_{\max } A_{\min }}
$$

(b) "Convexity (clustering Index)" assesses whether the place is a convex or concave space (Turner et al., 2001). A place with convexity equal or approximate to 1 is conceived as more integrated and usually in a regular shape. On the contrary, a place with convexity close to 0 has more occluding edges and tends to be fragmented. Observers may feel unsafe, and potential threats in such places as more areas are blocked behind. The formula is listed below (Batty, 2001). Where "i" denotes the observation point; $Z_{i}$ is the isovist field at point $i ; n_{i}$ is the number of 
grids in $Z_{i} ; E\left(Z_{i}\right)$ is the sum of visual segments in $Z_{i} ; \gamma_{i}$ is the convexity of $Z_{i} ; A_{i j}$ and $A_{i k}$ are the total line segments connected with point $i$; and $A_{i k}$ represents the line segments disjoined from point $i$.

(c) "Circularity (compactness)" measures the roundness of space. An isovist with higher circularity means it is more compact and closer to a round shape (Batty, 2001). While a lower circularity means the isovist is in a linear shape with a strong sense of direction (McCluskey, 1979; Adnan \& Yunus, 2012). The formula is as follow. Where $A_{i}$ is the area of $Z_{i}: P_{i}$ is the perimeter of $Z_{i}$ : and $\psi_{i}$ denotes the circularity of $Z_{i}$.

$$
{ }_{i j}=\frac{A_{i}}{\left(\frac{P_{i}^{2}}{4}\right)}
$$

Isovist analysis result

The spatial features of the historical district are translated into isovist fields through the computation. Fig. 1 (a) measures the relative area of the isovist fields. It presents a clear difference between the traditional alleys and broad-and-straight planned streets. The relative standard helps to depict the transition of isovist fields from a narrow space to a spacious one. Because of the curvilinear and narrow properties, the isovists in the alleys are relatively smaller, and observers could not acquire much information from the environment.
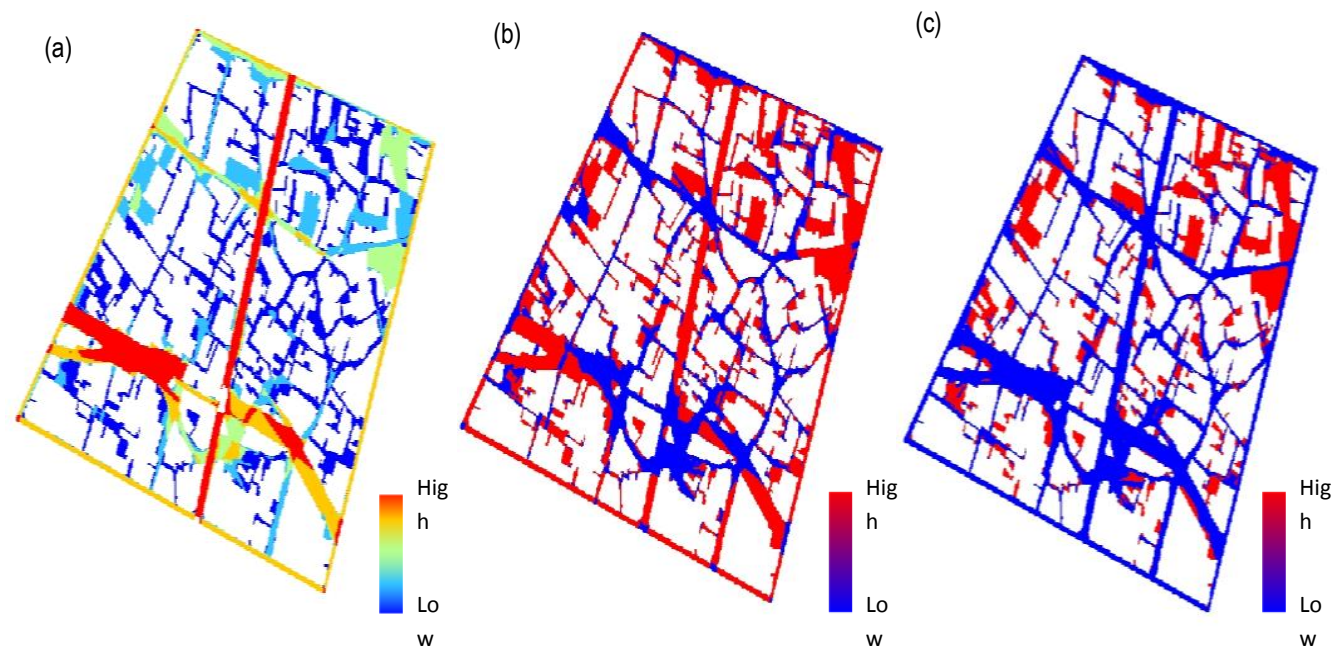

Fig. 1. The isovist analysis results of the research site: (a) Relative area; (b) Convexity; (c) Circularity.

$$
\begin{aligned}
A_{i j} & =\left\{\begin{array}{l}
1, j \in Z_{i} \\
0, \text { otherwise }
\end{array}\right\} \\
n_{i} & =\sum_{j=1}^{n} A_{i j} \\
i_{i j} & =\left(\frac{E\left(Z_{i}\right)}{n_{i}^{2}}\right)=\frac{\sum_{j=1}^{n} A_{i j} \sum_{k=1}^{n} A_{i k} A_{k j}}{\left(\sum_{j=1}^{n} A_{i j}\right)^{2}}
\end{aligned}
$$


Fig. 1 (b) and (c) show the convexity and the circularity index respectively. From the illustration (b), one can find a fusion of integrated (or convex) and fragmented (or concave) spaces created by the circuitous and irregular streetscape. The result indicates frequent (and sudden) changes of atmosphere in the environment. In Comparison with (b), the last illustration shows that most convex spaces are linear, forming more dynamic spaces rather than stopping points.

The computational results imply that observers in the traditional alleys have to move constantly in order to develop the sense of place and get enough information about the area. It also suggests intensive execution processes for observers when navigating in the changeful and juxtaposing spaces.

\section{Empirical study: wayfinding experiment}

The isovist analysis identifies the spatial characteristics and properties of the historical quarter. According to Tolman (1948), spaces are highly related to the forming of cognition in animals, which can even be mapped in our minds (Kara, 2013; Topcu \& Topcu, 2012). However, human's spatial behaviours are profoundly influenced by the other factor, i.e. social stimuli. Following the computational analysis, experiments are conducted on the same site to examine the wayfinding behaviours between different levels of social stimulations.

Subjects

Fifty-one undergraduate students (20 first-year students in 2013 and 31 first-year students in 2014) from the Dept. of Urban Planning, National Cheng Kung University, had participated as volunteers in the experiment. The subjects were between nineteen to twenty-two years of age, which 29 of total were female and 22 were male. All the eligible participants were nonlocal residents, unfamiliar to the site, and had not been to all the places (or local landmarks) around the area. As freshmen, they had not been trained for visual literacy yet (Bednarza \& Kemp, 2011; Yazdanfar, Heidari, \& Aghajari, 2015; Gibson, 1992) and had only the basic ability to interpret spatial representations. Subjects were randomly divided into small groups, pairs, and individuals to simulate different levels of social stimulation in the wayfinding experiment. Nine of the eighteen teams were of individual observers, five teams were in pairs, and four teams were in small groups (with 4 to 9 participants).

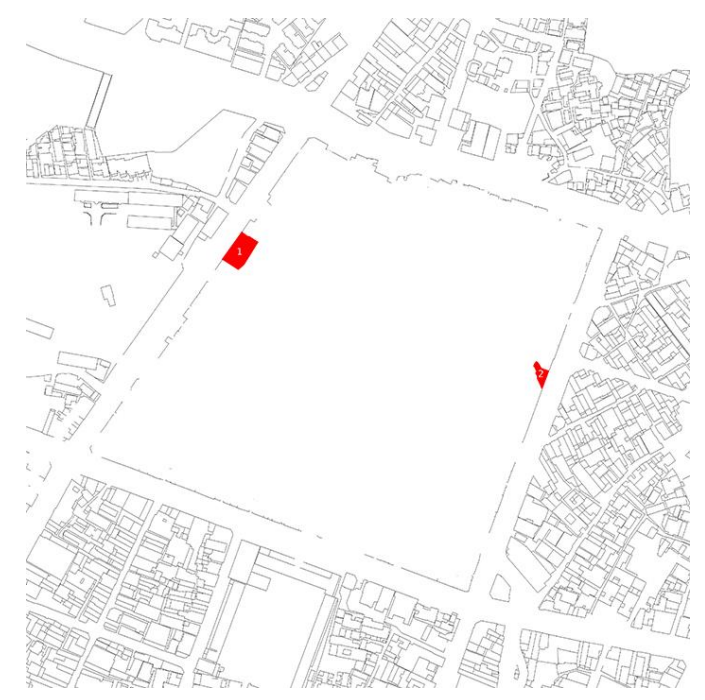

Fig. 2. The map of the historical district used for the experiment. (The red square on the left and the triangle on the right are the starting point and the end point.) 


\section{Procedure}

The experiments were conducted twice in December 2013 and December 2014, both from 9 am to $12 \mathrm{pm}$. The time was selected to avoid the heat and humid weather in the summer and more comfortable for pedestrians. Each subject was asked to walk at a normal pace and reach the goal in the shortest distance from the specific point in the historical district. All teams of participants were given a map and a GPS gadget. The map included the starting and the end point, and only buildings in the surrounding areas are shown on it (Fig. 2). The whole courses of navigation were recorded on GPS gadgets to reduce interference from the staffs. Each team had to wait for the previous teams to reach the goal before they set off in order to avoid influences on other observers.

\section{Findings \& Discussion}

The outcome of the wayfinding experiment is analyzed in general terms in the first section bellow to illustrate orientation in historical districts. The subsequent section focuses on the comparison between different numbers of subjects and their performances. One of the results (Individual no. 9) is ruled out because the subject did not follow the instruction to walk the shortest distance. The results from eight individual observers, five teams in pairs, and four teams in groups are presented as follows.

\section{Wayfinding behaviour in the historical quarter}

The GPS tracks (Google Maps, 2016) collected during subjects' navigation allow post studies on wayfinding behaviours to place characteristics. The data present an average (total) speed of $1.03(\mathrm{~m} / \mathrm{s})$ and the average moving speed of $1.31(\mathrm{~m} / \mathrm{s}$ ) (see the rightmost column in Table 1). The salient points of hesitation and pause are identified to examine the difference, as summarized in Fig. 3. It shows that most stopping points are in intersections where the isovist fields (see Fig. 1) are close to concave shapes (convexity close to 0 ) and have relatively smaller isovist areas (e.g. point $5,6,7,8$ ) or in transitions from big to small areas (e.g. point 1, 2, 3, 4). In some street sections, for instance from point 1 to 2 , point 2 to 6 , and point 3 to 4 to 5 , the subjects had also decreased their speed and paused more often. These places have bigger isovist areas and low convexities, which are described as more fragmented spaces in the isovist analysis.

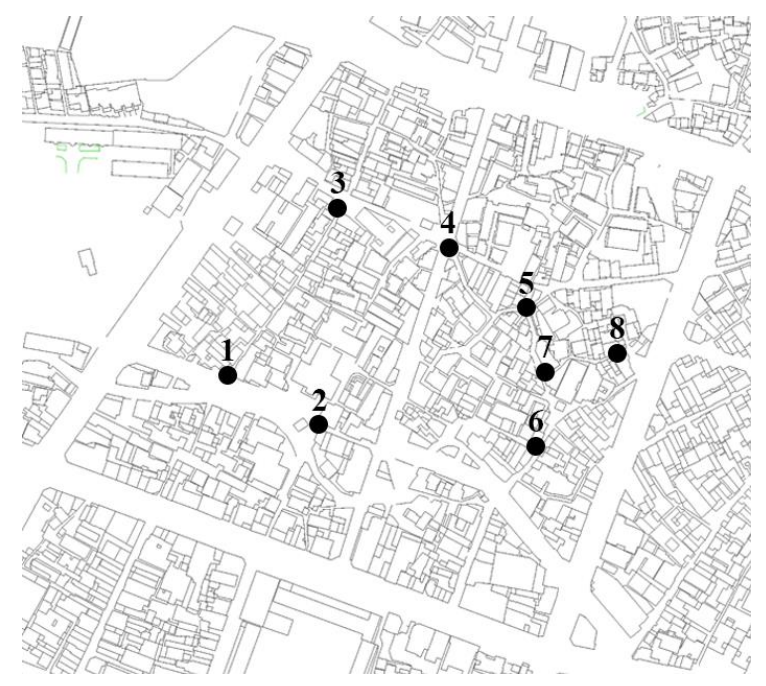

Fig. 3. The main stopping points of all teams. 
As the preceding study (Fig. 1 (c)) shows, the district primarily consists of dynamic spaces, and the squares (or convex spaces) are merely located around the starting and end points. The consistent circularity of the experimental site prompts the observers to move continuously. However, the unpredictable street spaces had caused them to slow down occasionally. The tracks have demonstrated corresponding changes between velocities and different areas and convexities of isovist fields.

In spaces with small isovist areas, the visible fields afford the observers limited information about the environment that they tend to hesitate before entering the unfamiliar places, or hover around to figure out what's ahead. The circumstance becomes obvious in the street junctions or between contrasting isovist areas, in which the lack of information makes it difficult for participants to orientate. As the places with low convexity, the many occluding edges block the observers' vision, providing fewer surfaces for perception. The sense of insecurity the environment affords in these observation points can be observed in the decrease of velocity.

Another noticeable outcome is that although in some places the isovist fields are relatively big, the observers still hesitate to move forward. It can be further explained by the low convexity properties. Despite the planned street crossing the district, the irregular lots connecting to it have reduced the broad-and-straight quality and made it almost as confusing as in the traditional alleys.

Table 1. The experiment result of individuals, pairs, and groups.

\begin{tabular}{|l|l|l|l|l|l|l|l|l|l|l|}
\hline & \multicolumn{3}{|c|}{ Individuals } & \multicolumn{3}{c|}{ Pairs } & \multicolumn{3}{c|}{ Groups } & Total \\
\cline { 2 - 13 } & Mean & SD & CV & Mean & SD & CV & Mean & SD & CV & Mean \\
\hline Distance (m) & 831.25 & 266.96 & 0.32 & 582.60 & 155.43 & 0.26 & 633.00 & 169.69 & 0.26 & 711.47 \\
\hline Avg. (total) speed (m/s) & 1.09 & 0.06 & 0.06 & 1.07 & 0.12 & 0.12 & 0.86 & 0.13 & 0.15 & 1.03 \\
\hline Avg. moving speed (m/s) & 1.32 & 0.12 & 0.09 & 1.36 & 0.18 & 0.13 & 1.21 & 0.33 & 0.27 & 1.31 \\
\hline Pause (minute) & $01: 58$ & & & $02: 09$ & & & $03: 37$ & & & \\
\hline
\end{tabular}

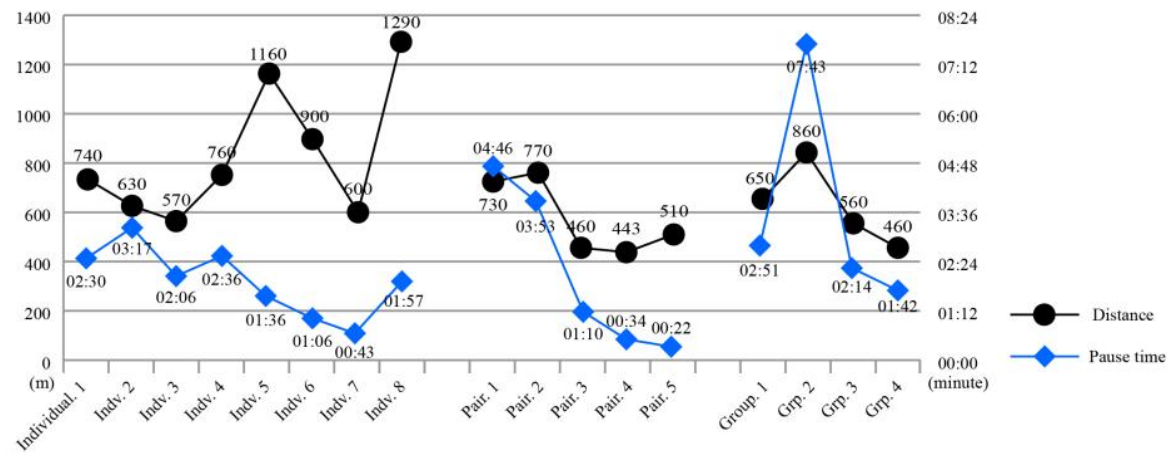

Fig. 4. Total distance and pause time of each team.

The number of subjects in a team

- $\quad$ Mean travel speed

The result shows distinguished differences between individuals, pairs, and groups of observers in the average (total) speed as well. Individual participants finished the task in the mean rate of $1.09 \mathrm{~m} / \mathrm{s}$, with a low coefficient of variation (CV) of 0.06 (Table 1). The statistics suggest that single observers tend to walk in similar speed when 
orienting in historical districts. As the number of participants increased, the mean velocity drops while the coefficient of variation becomes higher (pair: $M=1.07 \mathrm{~m} / \mathrm{s}, C V=0.12$; groups: $M=0.86, C V=0.15$ ). In comparison with individuals, the mean moving speed of groups is slightly slower, but the average stopping time is much longer than all the other groups.

- Total distance

Of the total distances the subjects had walked, the statistics demonstrate a more significant distinction between the three parties. Table 1 shows an average distance of 831 meters for individual observers to each the goal, 582 meters for pairs, and 633 meters for groups. In the first group of participants (Fig. 5 (a)), one individual observer had chosen to walk in the planned streets around the district instead of the traditional alleys. For the rest seven subjects, three of them had done the worst performances of all teams, and only one had taken the right path. For the second group (Fig. 5 (b)), three of the five pairs of participants had reached the destination in the shortest possible routes. As for the groups (Fig. 5 (c)), one team had finished the task in the shortest route, and the other three teams, though making some extra turns, were close to the general performances. Differences are evident in individual performances, but with additional companies, the results become more consistent. This can be verified in the coefficient of variation, that individual observers $(C V=0.32)$ varied among themselves much more than other parties (both $\mathrm{CV}=0.26$ ).

(a)

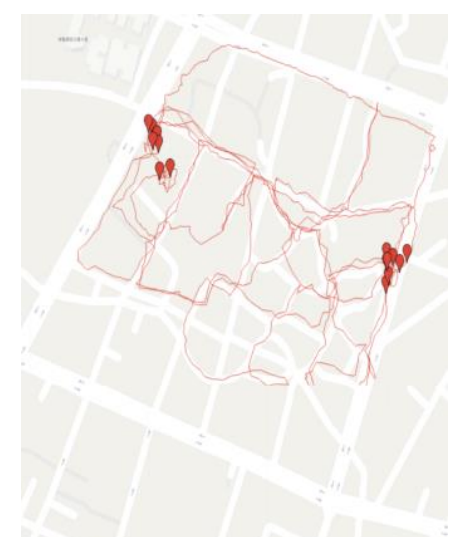

(b)

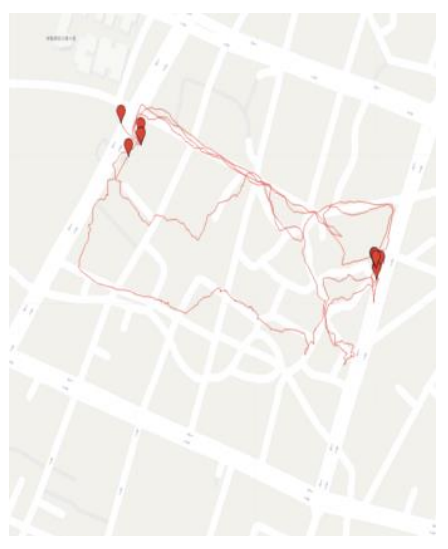

(c)

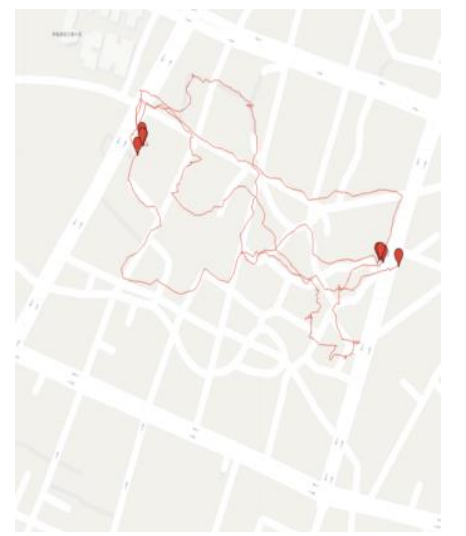

Fig. 5. The GPS tracks of the subjects in Tainan historical district (Google Maps, 2016): (a) Individuals; (b) Pairs; (c) Groups.

The result shows a modification of the subjects' wayfinding behaviours when multiple participants are engaged. Despite the influence of social stimulations changing from team to team, it nevertheless indicates the occurrence of communication between subjects and a major improvement in orientation and route choices. It is also important to note that pair observers stand out from the others with the best performances in the experiment.

Regarded as an execution process, wayfinding is highly related to the causality between perception and action. When two subjects are navigating, the reciprocal interaction helps each other to obtain more information than one could get from the environment, thus achieving better performances. However, a closer look at the teams with many observers, it becomes clear that those spent more time on making choices had finished in longer distances (Fig. 4). The case could be explained by the theory of affordance proposed by Gibson (1979). Among the group participants, the animate environments afford more to the observers than physical environments and lessen the attention paid to the surrounding invariant structures. It becomes more of a decision-making process in groups' wayfinding courses, rather than direct responses to the visual perception in individual or pair observers. 


\section{Conclusion}

As the synthesis of urban forms from different periods, the historical district provides pedestrians with complex and dynamic streetscapes. The varying street widths, irregular shapes, and changeable atmosphere require intensive execution processes during navigation, making it the perfect site to observe wayfinding behaviours. Inasmuch as they constitute people's cognition, the place characteristics and associated spatial behaviours can be predicted in isovist analysis.

However, the physical environment is inseparable from the animate environment (Gibson, 1979), and people do not only respond to spatial representations; they interact with each other. The research puts forward the influence of social interactions during wayfinding. When an observer is navigating, the spatial behaviours can be seemed as a mere response to the transformation of invariant structures of the environment, based on one's ability to perceive and past experiences (Parvaneh, Arentze, \& Timmermans, 2012; Othman, Nishimura, \& Kubota, 2013). While for group observers, the course becomes a decision-making between each member's past perceptions. The exchange of knowledge allows the subjects to enhance precision in orientation, which has been proved in the experiment.

There are also limitations in the research that should be mentioned. First of all, the moving speed, which is closely linked to the observer's perception, varies from person to person. It would be more precise to apply a relative standard to eliminate the difference. However it isn't significant in the study and so is ignored. Secondly, a major constraint is brought up for conducting experiments in real settings. In order to control the experiment in the open environment, the staffs had to follow behind to ensure safety and record the whole course. It is inevitable for the subjects to aware that they are under tests, and the staffs' presence more or less affects them. The influence is hard to measure, yet is still unavoidable in the experiment.

Moreover, though the present samples have verified the influence of social interactions, studies are expected for deeper investigations. The participant's gender, age, strategies and visual literacy, etc. may all affect social stimulations and wayfinding performances, and thus need to be scrutinized with large samples. Long been omitted, the mechanism of social stimuli and the interplay between different factors during navigation await further examination in detail.

\section{Acknowledgements}

The work described in this paper is partially supported by the Ministry of Science and Technology (Project No. MOST 104-2621-M-006-012-) and the Ministry of Education (The Aim for the Top University Project to the National Cheng Kung University, NCKU) of TAIWAN(ROC).

\section{References}

Abbasia, A., Alalouchb, C., \& Bramley, G. (2016). Open Space Quality in Deprived Urban Areas: User Perspective and Use Pattern. Social and Behavioral Sciences, 216, 194-205.

Adnan, F., \& Yunus, R. M. (2012). The Influence of Curvilinear Architectural Forms on Environment-Behaviour. Social and Behavioral Sciences, 49, 341-349.

Adolph, K. E., \& Kretch, K. S. (2015). Gibson's Theory of Perceptual Learning. In H. Keller (Developmental Section Ed.), International Encyclopedia of the Social and Behavioral Sciences, (2nd ed., Vol.10, pp.127-134). New York, NY: Elsevier.

Batty, M. (2001). Exploring isovist fields: space and shape in architectural and urban morphology. Environment and Planning B: Planning and Design, 28, 123-150.

Bednarz, R. A., \& Lee, J. (2011). The components of spatial thinking: empirical evidence. Social and Behavioral Sciences, 21, $103-107$.

Bednarza, S. W., \& Kemp, K. (2011). Understanding and nurturing spatial literacy. Social and Behavioral Sciences, 21, 18-23.

Benedikt, M. L. (1979). To take hold of space: isovist and isovist fields. Environment and Planning B, 28, 47-65.

308 
Benedikt, M. L., \& Davis, L. S. (1979). Computational Models of Space: Isovists and Isovist Fields. Computer Graphics And Image Processing, $11,49-72$.

Cenani, S., Arentze, T. A., \& Timmermans, H. J. P. (2012). A Cognitive Learning Model for Dynamic Activity-travel Patterns. Social and Behavioral Sciences, 54, 580-588.

Chandraa, S., \& Bhartib, A. K. (2013). Speed Distribution Curves for Pedestrians During Walking and Crossing. Social and Behavioral Sciences, $104,660-667$.

Cullen, G. (1961). The Concise Townscape. New York: Routledge.

Durairaj, K., \& Umar, I. N. (2015). A Proposed Conceptual Framework in Measuring Social Interaction and Knowledge Construction Level in Asynchronous Forum among University Students. Social and Behavioral Sciences, 176, 451-457.

Evans, G. W., Fellows, J., Zorn, M., \& Doty, K. (1980). Cognitive Mapping and Architecture. Journal of Applied Psychology, 65(4), 474-478.

Franz, G., \& Wiener, J. M. (2005). From Space Syntax to Space Semantics: A Behaviorally and Perceptually Oriented Methodology for the Efficient Description of the Geometry and Topology of Environments. Environment and Planning B Planning and Design, 35(4), 574-592.

Gibson, J. J. (1960). The concept of the stimulus in psychology. American Psychologist, 15, 694 - 703. Reprinted in Reed, E., \& Jones, R. (Eds., 1982), Reasons for realism: selected essays of James J. Gibson (Chapter 4.3: The concept of the stimulus in psychology) (pp. $333-349$ ). Hillsdale, NJ: Lawrence Erlbaum Associates.

Gibson, J. J. (1966). The Senses Considered as Perceptual Systems. Boston: Houghton-Mifflin.

Gibson, J. J. (1979). The ecological approach to visual perception. Boston: Houghton Mifflin Company.

Gibson, E. J. (1992). How to think about perceptual learning: Twenty-five years later. In H. L. Pick, P. van den Broek \& D. C. Knill (Eds.), Cognition: Conceptual and methodological issues (pp.215-237). Washington, D. C.: American Psychological Association.

Ghoomi, H. A., Yazdanfar, S. Hosseini, S., \& Maleki, S. N. (2015). Comparing the Components of Sense of Place in the Traditional and Modern Residential Neighborhoods. Social and Behavioral Sciences, 201, 275-285.

Google Maps. (Cartographer) (2016). The GPS tracks of the subjects in Tainan historical district [Street map]. Retrieved from https://www.google.com.tw/maps/@23.0007124,120.2034324,17.92z/data=!4m2!6m1!1sziHRpNNb6MCc.k1bO3qg476e0?hl=en.

Hashim, M. S., \& Said, I. (2013). Effectiveness of Wayfinding Towards Spatial Space and Human Behavior in Theme Park. Social and Behavioral Sciences, 85, 282-295.

Hussain, K. A. M., \& Ujang, N. (2014). Visitors' Identification of Landmarks in the Historic District of Banda Hilir, Melaka, Malaysia. Social and Behavioral Sciences, 153, 689-699.

Imani, F., \& Tabaeian, W. (2012). Recreating mental image with the aid of cognitive maps and its role in environmental perception. Social and Behavioral Sciences, 32, 53-62.

Ittelson, W. H. (1973). Environment Perception and Contemporary Perceptual Theory. In Ittelson, W. H (Ed.), Environment and Cognition (pp.141-154). New York: Seminar Press.

Ja'afara, N. H., Sulaimanb, A. B., \& Shamsuddinb, S. (2012). The Contribution of Landscape Features on Traditional Streets in Malaysia. Social and Behavioral Sciences, 50, 643-656.

Kara, B. (2013). Landscape Design and Cognitive Psychology. Social and Behavioral Sciences, 82, 288-291.

Kato, Y., \& Takeuchi, Y. (2003). Individual differences in wayfinding strategies. Journal of Environmental Psychology, 23, 171-188.

Koseoglu, E., \& Onder, D. E. (2011). Subjective and objective dimensions of spatial legibility. Social and Behavioral Sciences, 30, 1191-1195.

Kozlowski, L. T., \& Bryant, K. J. (1977). Sense of direction, spatial orientation, and cognitive maps. Journal of Experimental Psychology. Human Perception and Performance, 3, 590-598.

McCluskey, J. (1979). Road Form and Townscape, (2nd edition). Oxford, Boston. 
Meilinger, T., Franz, G., \& Bülthoff, H. H. (2012) From isovists via mental representations to behaviour: first steps toward closing the causal chain. Environment and Planning B: Planning and Design, vol. 39, p. 48-62.

Michaels, C. F. (2000) 'Information, Perception, and Action: What Should Ecological Psychologists Learn From Milner and Goodale (1995)?', Ecological Psychology, 12:3, 241-258, DOI: 10.1207/S15326969EC01203_4.

Mohammad, N. M. N., Saruwoono, M., Said, S. Y., \& Hariri, W. A. H. W. (2013). A Sense of Place within the Landscape in Cultural Settings. Social and Behavioral Sciences, 105, 506-512.

Monfared, N. S. S., \& Yazdanfar, S. A. (2015). Model of Perceptional Concepts and Related Physical Principle for Participatory Local Center: Chizar local community in Tehran as a case study. Social and Behavioral Sciences, 170, 78-88.

Neufert, E. (2009). Bauentwurfslehre. Grundlagen, Normen, Vorschriften über Anlage, Bau, Gestaltung, Raumbedarf, Raumbeziehungen, Maße für Gebäude, Räume, Einrichtungen, Geräte mit dem Menschen als Maß und Ziel. Handbuch für den Baufachmann, Bauherrn, Lehrenden und Lernenden. 39th edition. Wiesbaden: Vieweg+Teubner and GWV Fachverlage GmbH.

Othman, S., Nishimura, Y., \& Kubota, A. (2013). Memory Association in Place Making: A review. Social and Behavioral Sciences, 85, 554-563.

Parvaneh, Z., Arentze, T., \& Timmermans, H. (2011). A Simulation Model Assessing Impacts of Advanced Information and Communication Technologies on Activity-Travel Patterns. Social and Behavioral Sciences, 20, 236-243.

Parvaneh, Z., Arentze, T., \& Timmermans, H. (2012). Understanding Travelers' Behavior in Provision of Travel Information: A Bayesian Belief Approach. Social and Behavioral Sciences, 54, 251-260.

Passini, R. (1980/1981). WAYFINDING: A CONCEPTUAL FRAMEWORK, Urban Ecology, 5, 17-31.

Passini, R. (1984). Spatial Representations, A Wayfinding Perspective. Journal of Environmental Psychology, 4, 153-164.

Passini, R. (1996). Wayfinding design: logic, application and some thoughts on universality. Design Studies, 17, 319-331.

Runcharoen, S. (2014). The Development of Social Interaction of Children with Autism in Inclusive Classrooms. Social and Behavioral Sciences, $116,4108-4113$

Shamsuddina, S., Sulaimana, A. B., \& Amatb, R. C. (2012). Urban Landscape Factors That Influenced the Character of George Town, Penang Unesco World Heritage Site. Social and Behavioral Sciences, 50, 238-253.

Shamsuddina, S., Bahauddinb, H., \& Azizc, N. A. (2012). Relationship between the Outdoor Physical Environment and Student's Social Behaviour in Urban Secondary School. Social and Behavioral Sciences, 50, 148-160.

Stamps, A. E. III (2005). Isovists, enclosure, and permeability theory. Environment and Planning B: Planning and Design, 32, 735-762.

Takeuchi, Y. (1992). Sense of direction and its relationship with geographical orientation, personality traits and mental ability. Japanese Journal of Educational Psychology, 40, 47-53 (in Japanese with English abstract).

Tolman, E. C. (1948). Cognitive maps in rats and men. Psychological Review, 55, 189-208.

Topcu, K. D., \& Topcu, M.(2012). Visual Presentation of Mental Images in Urban Design Education: Cognitive Maps. Social and Behavioral Sciences, 51, 573-582

Turner, A., Doxa, M., O'Sullivan, D. \& Penn, A. (2001) From isovist to visibility graphs: a methodology for the analysis of architectural space. Environment and Planning B: Planning and Design, 28, 103-121.

Wakabayashi, Y., Itoh, S., \& Nagami, Y. (2011). The Use of Geospatial Information and Spatial Cognition of Taxi Drivers in Tokyo. Social and Behavioral Sciences, 21, 353-361.

Yazdanfar, S. A., Heidari, A. A., \& Aghajari, N. (2015) Comparison of Architects' and Non-Architects' Perception of Place. Social and Behavioral Sciences, 170, 690-699. 